\title{
An Improved Parallel Inverse Design Method of EMU Wheel Profile from Wheel Flange Wear Viewpoint
}

\author{
Wenjuan Ren $\left(\mathbb{D},{ }^{1,2}\right.$ Li Li $\left(\mathbb{D},{ }^{1}\right.$ Dabin Cui $\mathbb{D}^{1},{ }^{1}$ and Guangxiong Chen ${ }^{1}$ \\ ${ }^{1}$ Southwest Jiaotong University, Chengdu 610031, Sichuan, China \\ ${ }^{2}$ Sichuan College of Architectural Technology, Chengdu 610399, China \\ Correspondence should be addressed to Dabin Cui; cdb1645@163.com
}

Received 13 September 2020; Revised 10 December 2020; Accepted 21 December 2020; Published 13 January 2021

Academic Editor: Giuseppe Ruta

Copyright ( 2021 Wenjuan Ren et al. This is an open access article distributed under the Creative Commons Attribution License, which permits unrestricted use, distribution, and reproduction in any medium, provided the original work is properly cited.

An improved parallel inverse design method is proposed for wheel profile optimization. The dominant merit of this method is the ability to automatically search the target performance curve and obtain the optimized profile without artificial experience. With the help of vehicle system dynamic theory, an EMU model has been established in Simpack, and the dynamic performance is calculated with two profiles, i.e., optimization profile and original profile. The contact and mechanical characters are analyzed by Hertz's theory, Kalker global algorithm, and CONTACT program. It is found that the rolling radius difference (RRD) with the optimization profile is higher than the original one, especially when the lateral displacement is greater than $3 \mathrm{~mm}$. The creep force density with the optimization profile is significant with a wheelset displacement of $6 \sim 9 \mathrm{~mm}$. Compared with the original one, the distribution of contact points with the optimization profile is more uniform, and the contact position is more biased towards the root of the wheel flange. It means the optimization profile can provide higher RRD value and creep force with large lateral displacement, which is beneficial for reducing wheel flange wear. The dynamic simulation indicates that the optimization profile can help reduce the wheel flange force and wheel flange wear in a sharp curve. Meanwhile, the dynamic behaviors and wheel tread wear on a tangent track or a large curved track are also favorable with the optimization profile.

\section{Introduction}

High-speed railway plays an increasingly important role in the railway system because of its safety, convenience, comfort, and large transport capacity. With the increase in the speed and carrying capacity of the EMU, the wear problems stand out [1]. The high-speed railways are mainly composed of tangent track and large curved track, and the matching performance between the wheel tread and rail has improved by wheel profile optimization [2-6]. However, the sharp curves must exist near the station yard, and the flange wear caused by it cannot be ignored [7]. Researches on the optimal design of wheel profile for wheel flange wear have not been fully developed at home and abroad. The stress concentration caused by the contact between wheel flange and rail gauge corner is the main reason for wheel flange wear. A large wheel flange force under a sharp curve will inevitably cause severe wheel flange wear and side rail wear, which becomes the decisive factor for rail replacement on a curved track [8].

Some researchers paid attention to the parameters, which could result inside rail wear, and pointed out the measures to alleviate it [9-11]. From the perspective of the wheel/rail relationship, reducing the side wear of the rail means the wheel flange wear can decrease to a certain extent. Some scholars considered the influence of different factors on wheel flange wear and the mechanism for it, and the corresponding measures are presented [12-15]. Ren et al. [16] calculated the effect of different wheel flange thickness on wheel/rail matching performance. The results showed that the thinner the wheel flange was, the more serious the flange wear would be. The abnormal flange wear can affect the wheel/rail contact performance, matching state, and vehicle dynamic performance $[17,18]$. And the wheel/rail profile optimization, which can improve the wheel/rail matching relationship, has a significant effect on reducing 
wheel flange wear $[14,15]$. Ren et al. [16] believed that increasing the equivalent conicity of the wheel profile could effectively reduce wheel flange wear.

Based on the above analysis, the problems related to wheel flange wear have always been the focus of researchers' attention, and reducing flange wear is the fundamental purpose of all studies. This paper takes the actual measurement of the wheel flange wear on an EMU line as the starting point and aims to achieve the goal of reducing flange wear by optimizing the wheel profile.

\section{Design Procedure}

2.1. Measured Flange Wear. A long-term tracking test of the wheel wear is performed on an EMU line. It shows that the areas of wheel profile show different degrees of wear after a considerable mileage. The description of a wheel profile is shown in Figure 1. Area A is the wheel tread zone, the wear of which is caused by the train operation on the mainline. When passing the middle radius curves, area $\mathrm{B}$ can affect the curve negotiation performance, and its wear mainly happens under this situation. Area $\mathrm{D}$ is the wheel flange section, and the flange wear appears on tight curves. Area $\mathrm{C}$ is the extension zone. As the severe wear of the wheel profile will lead to the degradation of wheel/rail matching performance, it must be lathed to raise the running behavior of the vehicle. The time interval between two adjacent wheel repairs is the so-called "lathing cycle." The difference between measured flange thickness and standard thickness is the absolute value of flange wear. The wheel flange wear under each repair cycle is given in Figure 2. The wear includes two parts, i.e., the flange wear caused by the operation of the vehicle and the amount of flange loss caused by wheel repair. It is clear that the initial wear is relatively small, and the wear becomes severer and severer as the repair cycle increased. At present, to guarantee the service life of the wheelset, the cutting volume of each repair cycle is as small as possible, and a flatpushing method of a reprofiling template is applied. The reprofiling wheelsets have a change on the wheel tread, which will cut down the equivalent conicity, as shown in Figure 3. With the increase of the repair cycle, the equivalent conicity is getting lower, which is unfavorable to the curving performance of the vehicle and the wheel flange wear. The measured results in Figure 2 are consistent with the scrapping situation of the wheelsets, which scrap due to flange wear. The shortening of the wheelset service life not only increases the operation and maintenance cost, but the wear will significantly reduce the wheel/rail matching performance, which in turn affects the safety, stability, and comfort of the vehicle operation. Therefore, it is urgent to solve the problem of high flange wear on this line.

\subsection{An Improved Parallel Inverse Optimization Method.} According to the literature [16], an effective way to reduce flange wear is to improve the curing behavior of the vehicle, which can be achieved by increasing the equivalent conicity. The inverse method can obtain an ideal performance index of wheel tread by adjusting the profile directly, and the goal

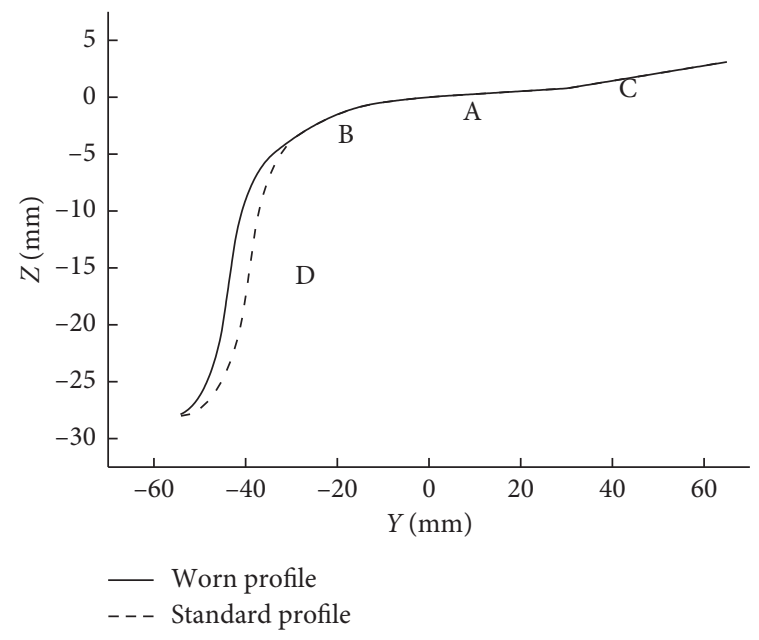

Figure 1: Description of wheel profile.

is clear and easy to achieve. The inverse method has been applied successfully in wheel profile design $[19,20]$. The main intention of this paper is to improve the abnormal wear of wheel flange on the measured line. The inverse method can solve the problem directly by profile optimization. However, the target performance curve in the inverse method needs to be set in advance. In the previous applications, no specific strategy and scheme for obtaining the target performance curve are presented. It builds mainly relying on designers' experience, which significantly restricts the application of this method. This paper proposes an improved parallel inverse method to get the expected wheel profile. In the proposed improved parallel inverse method, multiple threads can run simultaneously. It can automatically search for the optimal target performance curve effectively. With the help of the optimal target performance curve and relative calculation parameters, the traditional inverse method is applied to get the optimal wheel profile. The new approach is no longer depending on the design experience of the original inverse method while keeping its advantages of high calculation efficiency and good convergence.

The optimization process of the improved parallel inverse method mainly included two steps. In step 1, a model is built to find an optimal performance curve that satisfies the requirements; in step 2, the optimal performance curve is taken as the target performance curve, and the parallel inverse method is used to obtain the optimization profile. Reference [16] pointed out that increasing the equivalent conicity is an effective way to reduce the wheel flange wear. However, it will be singular with small lateral displacement, and the target equivalent conicity curve is difficult to get accurately. The rolling radii difference (RRD) is a geometric parameter directly related to equivalent conicity. The larger the rolling radii difference is, the larger the equivalent conicity will be, and vice versa $[21,22]$. Therefore, taking the RRD curve as the target performance curve is practicable.

In practice, when the lateral displacement of the wheelset exceeds $9 \mathrm{~mm}$, the contact between wheel flange and rail will appear. Therefore, it is feasible to increase the RRD value 


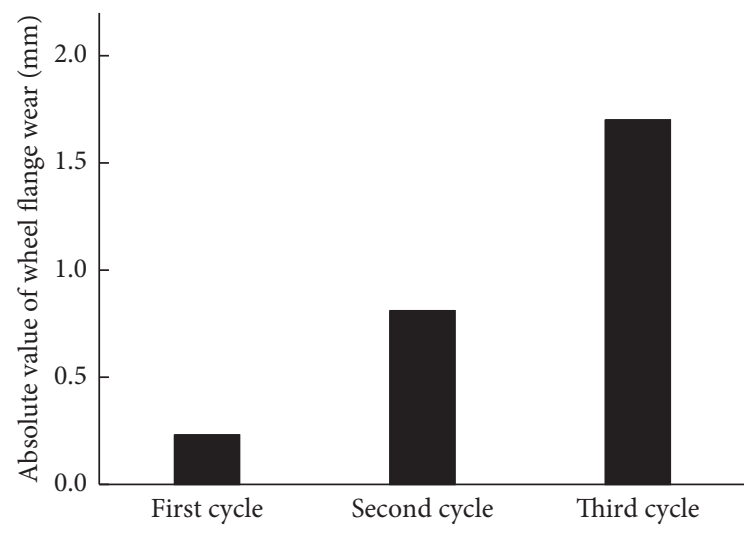

Figure 2: Measured wheel flange wear.

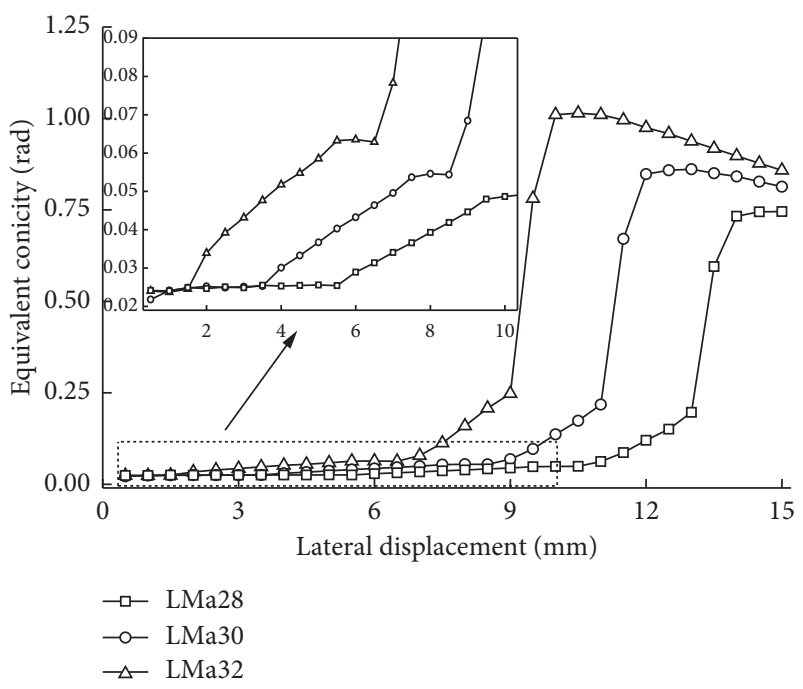

FIgURE 3: Equivalent conicity of different wheelsets.

within the range of $0 \sim 9 \mathrm{~mm}$ wheelset displacement so that the frequency of wheel flange contact with the rail will decrease, and the curve negotiation performance can improve. As the traditional inverse design method relies on experiences to obtain the target performance curve, the cubic spline function is chosen to establish the model to get the target RRD curve through automatic search. The control point distribution of the RRD performance curve is shown in Figure 4 . The increase of control points is conducive to the precise control of RRD value under each lateral displacement. But this will seriously affect the calculation efficiency and convergence. And too many control points will lead to the waveform of the RRD curve, which will affect the optimization results. Therefore, four nodes with a $3 \mathrm{~mm}$ displacement interval are selected to control the RRD curve. Point 0 and point 3 are fixed ones, and the abscissa of moving nodes, i.e., point 1 and point 2 , is set to be constant. The ordinates of point 1 and point 2 are variables. Then, the multiobjective optimization method is used to get the optimal RRD curve, that is, the target performance curve.

When establishing the objective function of the optimization model, the increase of the RRD value is achieved by adjusting the variables. However, in the solution process, countless combinations $(z 1, z 2)$ that meet a specific target value correspond to countless RRD curves, which will result in innumerable wheel profiles obtained by the inverse method. Additionally, the equivalent conicity is proportional to the rolling radii difference. The higher RRD value means a larger equivalent conicity, which will inevitably reduce the critical speed of the vehicle on the tangent track. To make the critical speed satisfy the operational requirements with the increase of equivalent conicity, the constraint function about critical speed must add to the model. Even though the wheel profile, which meets the conditions, can be obtained, it is still impossible to guarantee the optimal one. Therefore, except for the given constrain function, the critical speed-control term should add to the objective function to obtain a wheel profile with the highest critical speed, that is, the optimal profile. Moreover, as the RRD value of the optimal profile is required to increase with the increase of lateral displacement of the wheelset, the ordinates of moving nodes should be constrained.

In conclusion, the optimization model of objective performance curve established according to the design requirements is as follows:

$$
\begin{cases}\max & f(z)=0.7 \sqrt{\left(z_{1}-z_{1}^{0}\right)^{2}+\left(z_{2}-z_{2}^{0}\right)^{2}}+0.3 \frac{v}{1000} \\ & v>390 \mathrm{~km} / \mathrm{h} \\ \text { s.t. } & z_{0}+z_{2}>2 z_{1} \\ & z_{1}+z_{3}>2 z_{2},\end{cases}
$$

where $z_{i}(i=0,1,2,3)$ are the control node ordinates of the optimization profile RRD curve; $z_{i}^{0}(i=0,1,2,3)$ are the control node ordinates of the original profile RRD curve; and $w_{i}(i=1,2)$ is the weight coefficient of the objective function. In this paper, the purpose of wheel profile optimization is to reduce the wheel flange wear. $w_{1}=0.7$ and $w_{2}=0.3$ are selected, according to the comparative analysis of trial calculation. $v$ is the critical speed of optimization profile; $390 \mathrm{~km} / \mathrm{h}$ is the actual operating speed of the vehicle when considering safety factors. With the establishment of model (1), the target performance curve is no longer obtained by the empirical trial method in the previous application. Considering that the RRD curve function of the model (1) is difficult to establish by a specific function expression and the gradient of the RRD curve is also not available, the traditional optimization algorithm cannot solve the model. The Nelder-Mead [23] method is an optimization method that does not depend on gradient information $[6,20]$. And it can be used in model (1) to solve the RRD curve function to obtain the optimal RRD curve that meets the conditions. After gaining the target RRD curve, the wheel profile will be gotten by the original reverse design method. Figure 5 shows the program flowchart of the improved parallel reverse design method. In this figure, $\mu$ and $i$ are the numbers of 


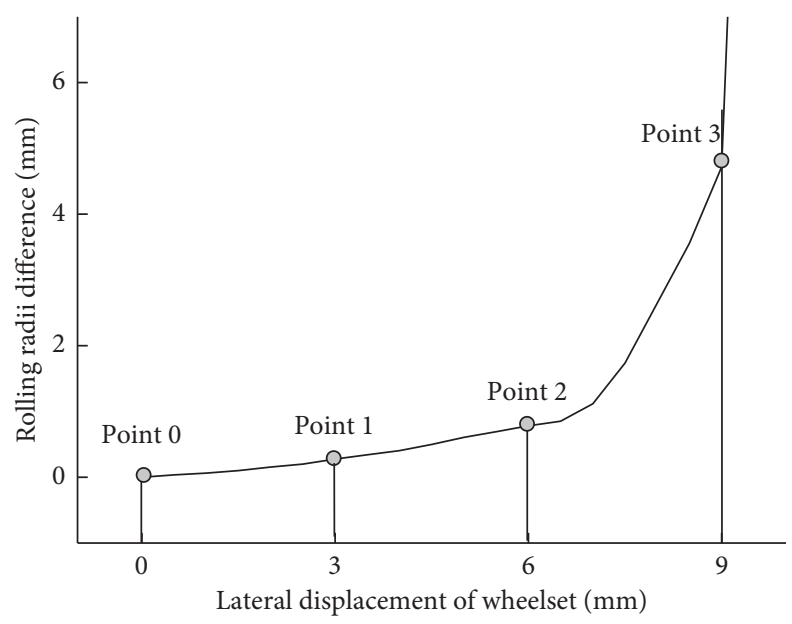

Figure 4: Control points distribution of the RRD curve.

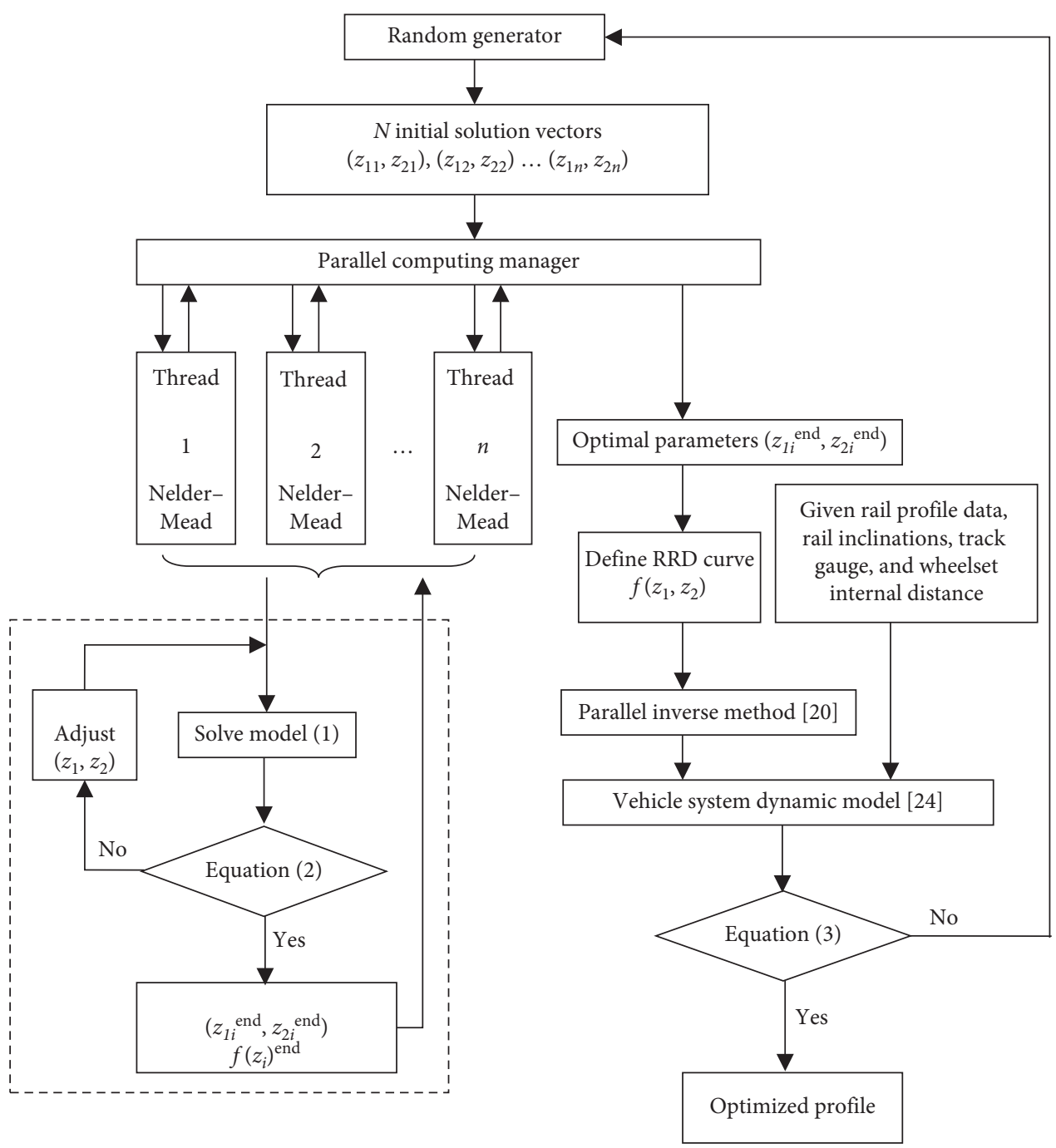

Figure 5: Program flowchart of the improved parallel inverse design method. 
iteration. $\varepsilon^{\prime}$ and $\varepsilon$ are the allowable error values. Equation (2) is the convergence criterion of the Nelder-Mead [23] method, and equation (3) is the cycle termination condition.

$$
\left\{\frac{1}{n+1} \sum_{i=1}^{n+1}\left[f\left(z^{i}\right)-f(\bar{z})\right]^{2}\right\}^{1 / 2}<\varepsilon^{\prime}
$$

where $z^{i}$ is the ordinate vector of group " $i$ " moving nodes and $z$ is the centroid of simplex composed of the ordinate vectors of the $n+1$ groups of moving nodes.

$$
\begin{aligned}
v & >\eta v_{0}, \\
f_{\mu}(z)-f_{\mu-1}(z) & <\varepsilon .
\end{aligned}
$$

The improved parallel reverse design method is a nested loop. Firstly, two groups $\left(z_{1 i}, z_{2 i}\right) i=1,2$ are set randomly, and the moving node ordinates $\left(z_{10}, z_{20}\right)$ of the original profile are given. For each group of the moving node ordinates, it can get one RRD curve. And three groups of objective function values $f_{1}(z), f_{2}(z)$, and $f_{3}(z)$ can be calculated by the parallel reverse design method and vehicle system dynamics model. Then, $f_{1}(z), f_{2}(z)$, and $f_{3}(z)$ are taken as the vertices to form the initial simplex $[24,25]$. Secondly, the Nelder-Mead [23] method is used to continuously adjust the ordinates $\left(z_{1}, z_{2}\right)$ of moving nodes to search the target RRD curve until the optimal RRD curve is found. Thirdly, after obtaining the target RRD curve, the parallel inverse method and vehicle system dynamics model [26] are used to get the target function value $f(z)$. Then, the procedure will judge whether $f(z)$ satisfies the loop termination condition. If it meets the requirements, the output wheel profile is the optimal profile. If not, the program will return to adjust the ordinates of the moving nodes until the optimal wheel profile appears.

\section{Results and Analysis}

The static contact characters and dynamical performance of the two profiles are calculated and compared. In particular, the wheel flange wear is analyzed. The distance between the backs of the wheel flanges is $1353 \mathrm{~mm}$, the rail gauge is $1435 \mathrm{~mm}$, and the rail cant is $1 / 40$. The influence of the wheelset yaw angle is not considered.

3.1. Wheel-Rail Contact Characters. The geometry of the optimization profile and the original one is shown in Figure 6. A clear difference appears in the region of the flange root. The slope in the flange root zone of the optimization profile is slightly higher than that of the original one, which is potential to increase the wheel flange conicity. Figure 7 describes the rolling radii difference between the two profiles. It shows that the RRD of the optimization profile is much higher when the lateral displacement is beyond $3 \mathrm{~mm}$. The larger RRD means larger equivalent conicity, which can improve the curving performance of the vehicle. The improved curve negotiation will reduce the contact possibility between wheel flange and rail, which is helpful to the reduction of flange wear. At the same time, the smaller RRD of the optimization profile within $3 \mathrm{~mm}$ can guarantee the straight-line running performance.

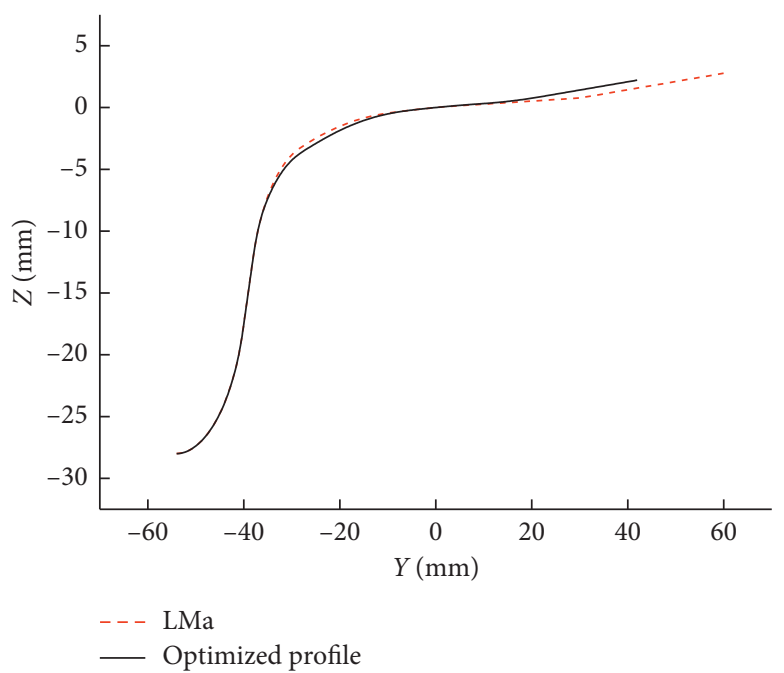

FIgURE 6: Comparison of optimization profile and original profile.

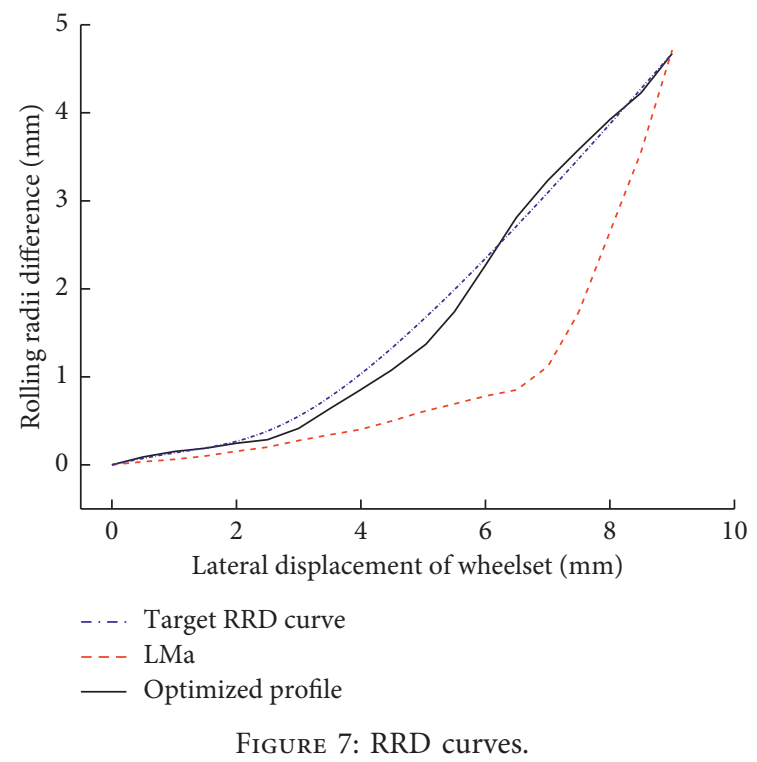

Under the static condition, Hertz's theory, Kalker global algorithm is applied to calculate the matching characters. Since the load distribution of the right wheel/rail does not change much with the lateral displacement of the wheelset, only the calculation results of the left wheel/rail are given in this paper. The maximum creep force density of the wheel/ rail is shown in Figures 8 and 9. The creep force density of the optimization profile is significantly higher with a lateral displacement of $6 \sim 9 \mathrm{~mm}$, which resulted from the larger RRD (see Figure 7). The increased longitudinal creep force of the optimization profile in Figure 9 can provide a greater guiding force for the vehicle to pass through the curve, and the curving performance is improved. Additionally, on a curved track, the greater lateral creep force of the optimization profile has an advantage in reducing the wheel flange force, thus improving the flange wear.

The wheel-rail contact state is considered with a lateral displacement of $-12 \mathrm{~mm} \sim 12 \mathrm{~mm}$. One contact position is 


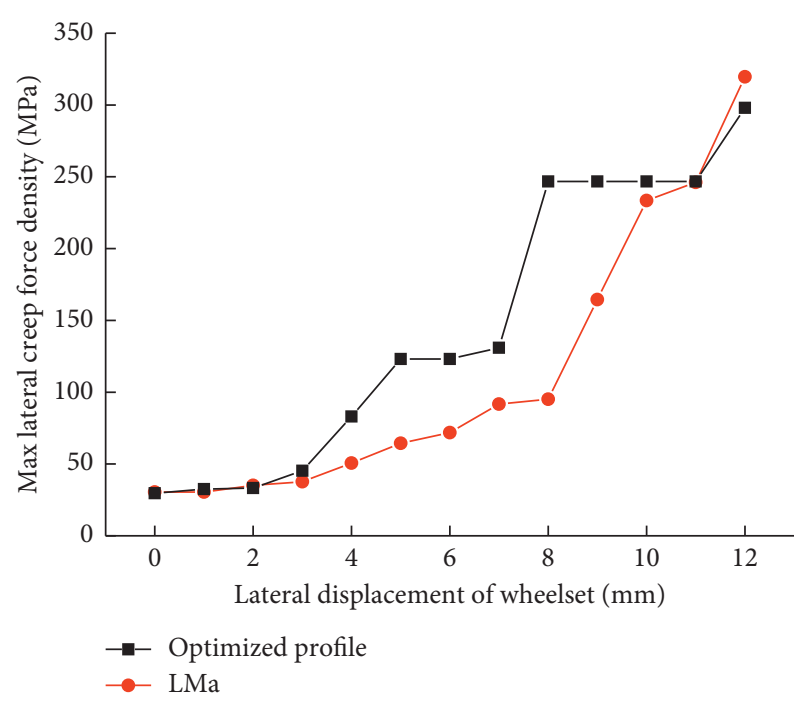

FIgURe 8: Maximum lateral creep force density.

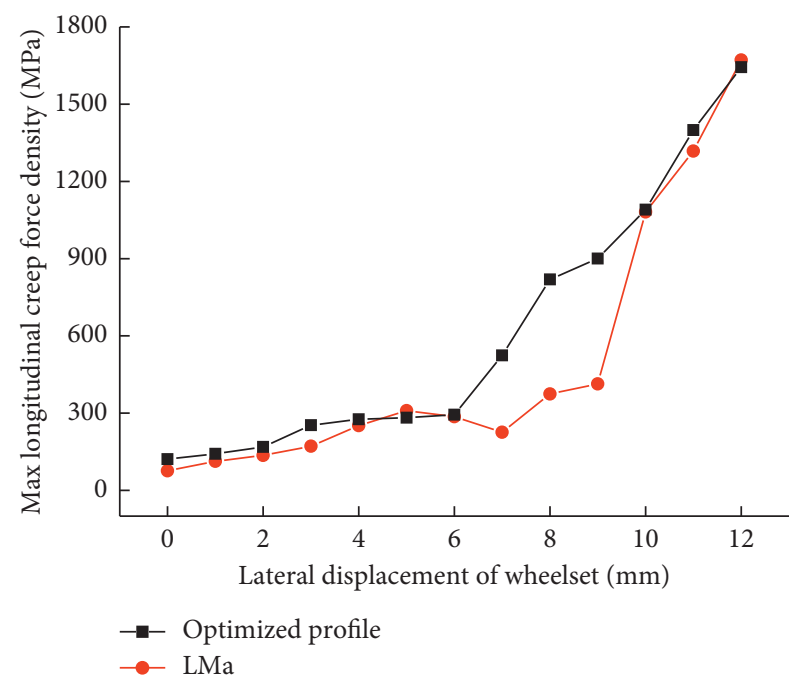

Figure 9: Maximum longitudinal creep force density.

calculated at an interval of $0.5 \mathrm{~mm}$. Figure 10 shows the distribution of contact points versus lateral displacement of the wheelset. The origin of the coordinate system in this figure is located at the nominal rolling circle of the whee, which is $70 \mathrm{~mm}$ away from the wheel back. The lines between the wheel and rail represent the contact points, and the value of the corresponding lateral displacement of the wheelset is shown above the wheel profile. It can be seen from Figure 10 that the contact points of the optimization profile and standard rail distribute uniformly, and the contact position tends to the flange root compared with the original one. Combined with Figures 7-10, it should be noticed that when the vehicle passes through a curved track, the optimization profile can provide higher rolling radii difference and creep force under the same lateral displacement. When the contact points are located at the flange section, the contact characters of the optimization profile have benefits for improving curving performance and reducing wheel flange wear.

The total area of the contact patch and the maximum positive pressure density relative to the lateral displacement of the wheelset are shown in Figures 11 and 12, respectively. The value of maximum positive pressure density is mainly related to the contact patch area. The larger the contact patch area is, the smaller the value of maximum positive pressure density is, and vice versa. Combined with Figures 11 and 12, it can be seen that, except for the initial position, the contact patch area of the original profile is always higher, especially when the lateral displacement of the wheelset is within 6-9 $\mathrm{mm}$. The reduction of the contact patch area of the optimization profile will increase the contact stress, which can cause more severe wear of wheel flange root. But at present, the abnormal wear of the wheelset in this highspeed line is the flange zone, not the root area of the flange.

3.2. Dynamic Behavior Analysis. According to the field test data, the wheel flange wears mainly occur under sharp curves, and the wear is severe. Therefore, the curve negotiation performance of the vehicle is primarily analyzed, and the straight-line running performance is verified.

3.2.1. Curve Negotiation Performance on Tight Curve. The lateral force and angle of attack, when the wheel flange is close to the rail, are responsible for the rate of wheel flange wear. On a tight curve, the dynamical performance of the vehicle at a low speed is calculated and compared, as shown in Figure 13. From Figure 13(a), it can be seen that the lateral displacement of two profiles is around $9 \mathrm{~mm}$, which can result in the contact between the wheel flange and rail and cause significant wear of wheel flange and rail gauge corner. In particular, the angle of attack of the optimization profile is smaller than that of the original one in the circle curve section, which is conducive to reducing the wheel flange wear. Additionally, the flange force produced by the contact between wheel flange and rail has a considerable influence on flange wear. Therefore, the stress condition is depicted in Figure 14. The curve parameters and vehicle speed are listed in Table 1.

It should be noticed that the lateral force of both original and optimization profiles is almost the same, which is because the wheel flange has already contacted the rail. The expression of lateral force after the wheel flange contacts rail is as follows [22, 27]:

$$
F_{\text {lateral }}=F_{N 2} \cos \tau+F_{N 1} \sin \gamma,
$$

where $F_{\text {lateral }}$ is the wheel-rail lateral force, $F_{N 2}$ is the normal force of contact point at wheel flange section, $F_{N 1}$ is the normal force of contact point at the wheel tread area, $\tau$ is the flange angle, i.e., 70 degrees, and $\gamma$ is the contact angle.

According to equation (4), when the lateral force $F_{\text {lateral }}$ is settled, the value of $F_{N 1} \sin \gamma$ will be the vital parameter that affects the flange force $F_{N 2}$. If the normal force $F_{N 1}$ is the same, the value of $\gamma$ will be the determining factor that influences the wheel flange force. Therefore, the normal force and contact 


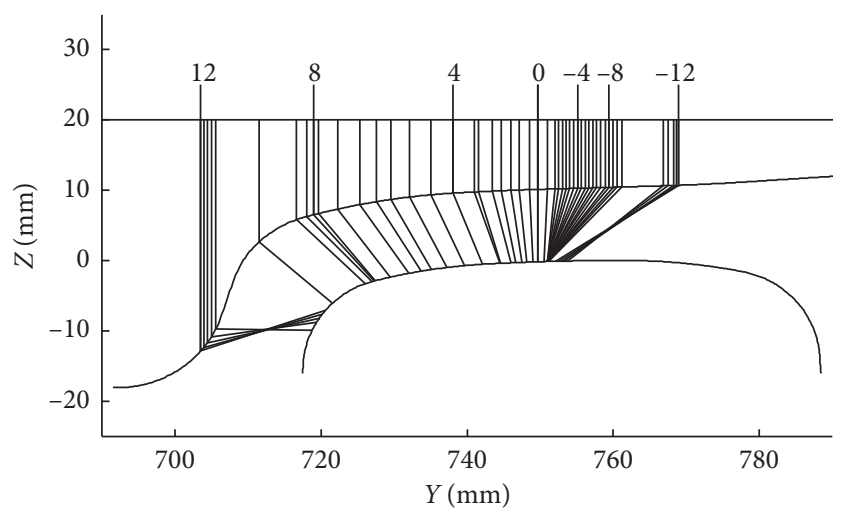

(a)

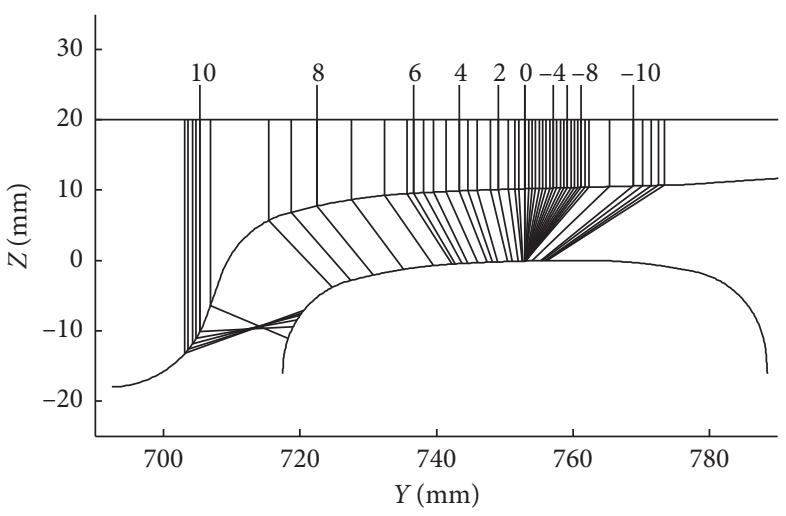

(b)

Figure 10: Position of contact points on the wheel and rail depending on lateral displacement of the wheelset. (a) OPT profileCHN60. (b) LMa-CHN60.

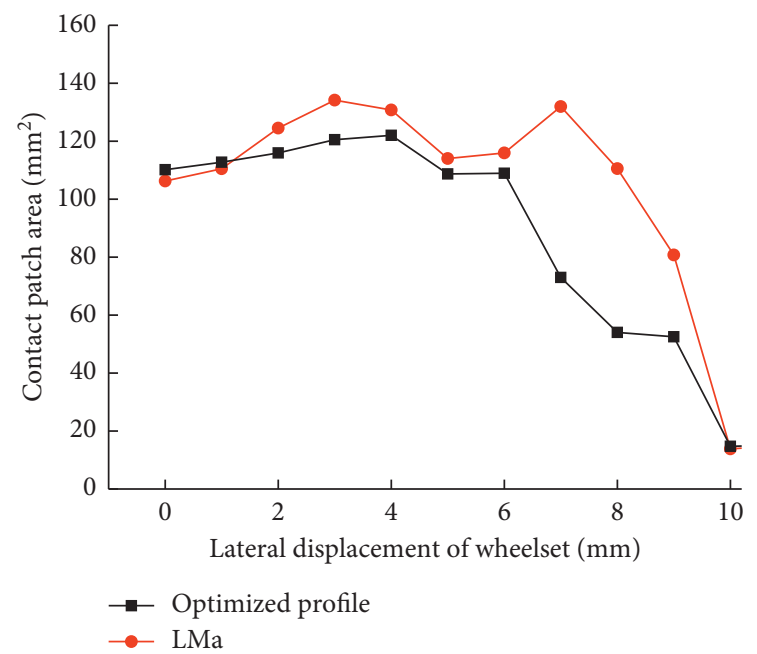

FIgURE 11: Contact patch area.

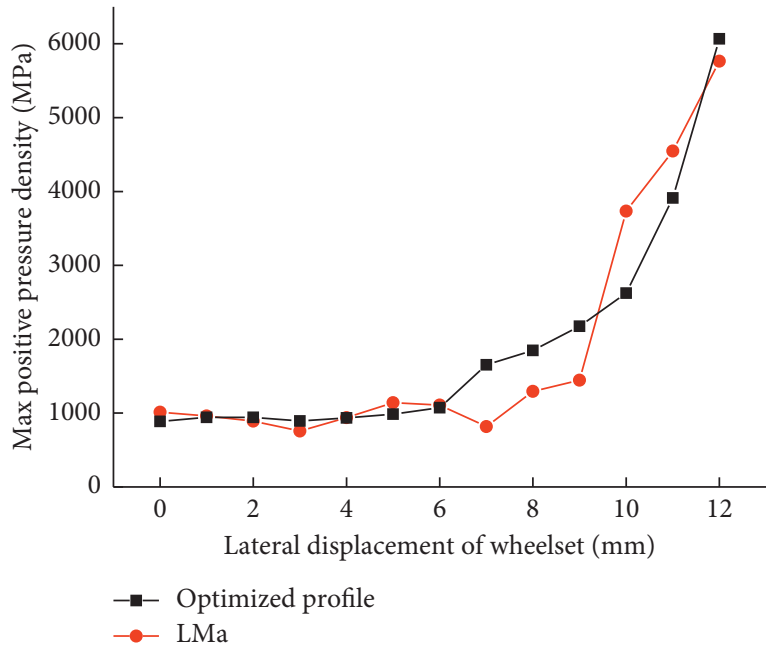

FIgURE 12: Maximum positive pressure density. angle are calculated, as shown in Figures 15 and 16. It can be seen that, compared with the original profile, the normal force of the optimization profile is slightly larger in the circle curve segment, and the contact angle is significantly larger in the whole lateral displacement range. The simulation results illustrate that the value of $F_{N 1} \sin \gamma$ of the optimization profile at the wheel tread is significantly larger than that of the original one, which can reduce the flange force and thus help improve the flange wear. In summary, the flange wear under the sharp curve is reduced by profile optimization.

Figure 17 presents the derailment coefficients of two profiles on the tight curve. In this figure, the derailment coefficients have a small float only in the transition curve section. In the circle curve section, the values are almost coincident. The maximum derailment coefficient of the two profiles in Figure 16 is about 0.4, which is less than the limit value 1 of the derailment coefficient specified by the national standard. Therefore, both of them can meet the safety requirements of vehicle operation. The simulation results of the sharp curve indicate that the optimization profile reduces the wheel flange wear effectively, and the purpose of profile optimization is achieved.

\subsubsection{Curve Negotiation Performance on Different Curve} Radii. To compare the curve negotiation performance of two profiles with different radii, the authors calculate the maximum lateral displacement of wheelset and wheel/rail lateral force, as shown in Figures 18 and 19. The figures show that both the lateral displacement and lateral force gradually increase with the decrease in the curve radius. It should also be noticed that the maximum lateral force of the two profiles has little difference, and the lateral displacement of the optimization profile is lower when the radius is greater than $1000 \mathrm{~m}$. Based on Figure 7, the higher RRD of the optimization profile improves the curving performance. According to the calculation program of wheel-rail contact points, the contact line, when the wheel flange is close to the 


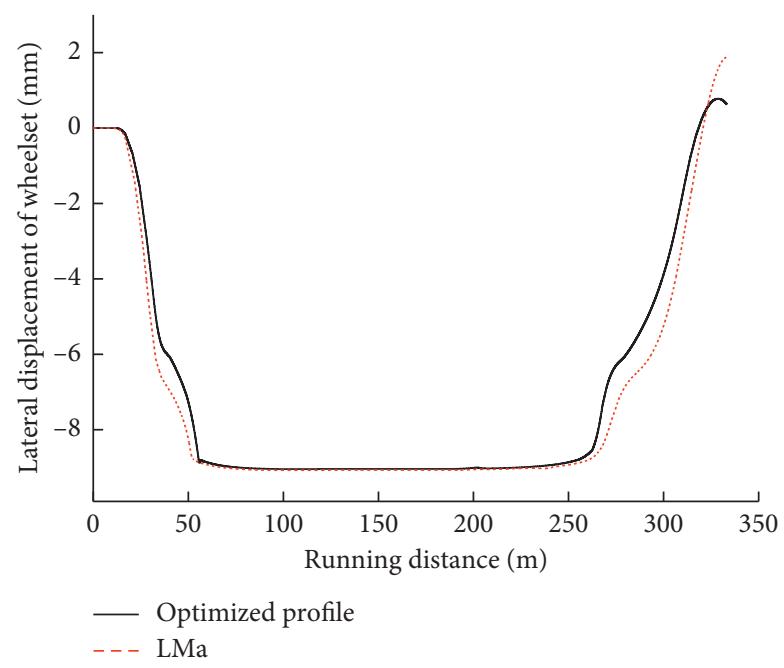

(a)

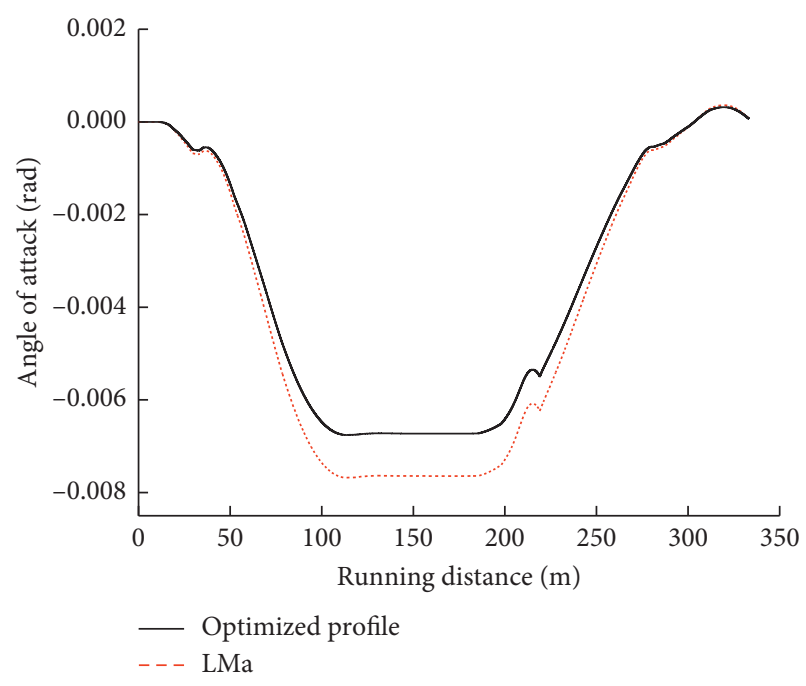

(b)

FIGURE 13: Dynamic performance of the wheelset. (a) Lateral displacement of the wheelset. (b) Angle of attack of the wheel and rail.

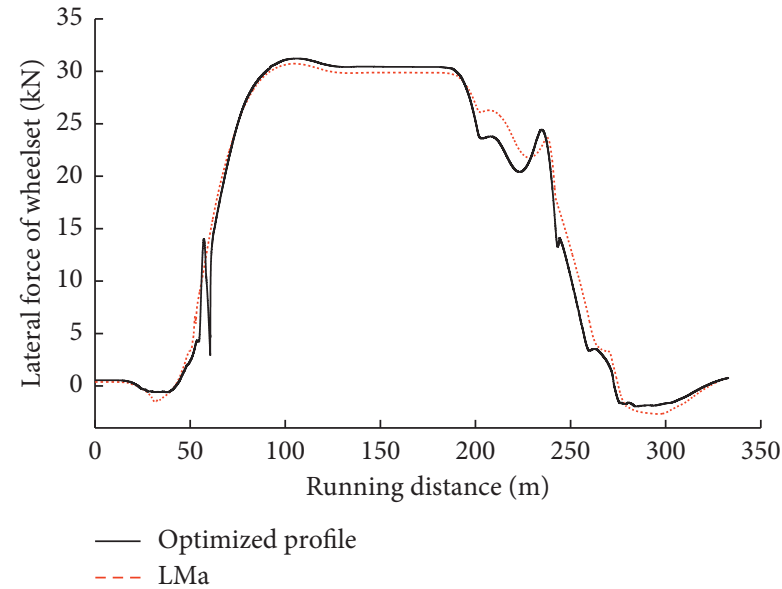

FIgURE 14: Lateral force of the wheel and rail.

TABLE 1: Curve parameters and vehicle speed.

\begin{tabular}{lcc}
\hline Curve radius $(\mathrm{m})$ & Cant $(\mathrm{mm})$ & Vehicle speed $(\mathrm{km} / \mathrm{h})$ \\
\hline 300 & 0 & 10 \\
\hline
\end{tabular}

rail, is given, as shown in Figure 18. It can be seen that when the wheel flange contacts the rail, the curve radius of the original profile is $800 \mathrm{~m}$, while the optimization profile is between $600 \mathrm{~m}$ and $700 \mathrm{~m}$. The wheel flange of the original profile is more likely to contact with rail gauge corner. Meanwhile, the lateral force of the optimization profile is larger in the case of $R<500 \mathrm{~m}$, which is beneficial to wheel flange forces. Moreover, the lower lateral force on the wheel tread area is favorable for reducing wheel-rail wear on a large curved track $(R \geq 800 \mathrm{~m})$.

For safety performance, the maximum derailment coefficients under different curve radius are depicted in Figure 20.

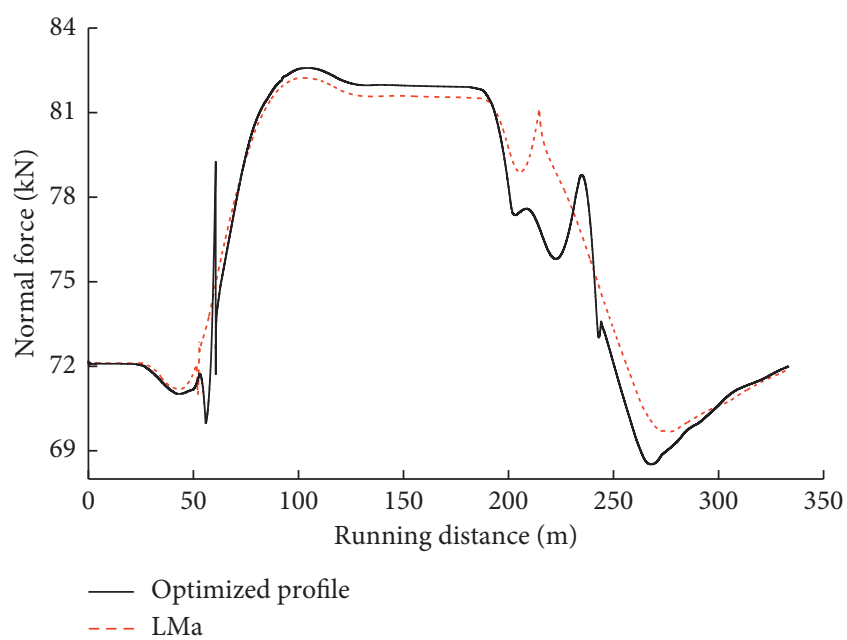

Figure 15: Normal force of the wheel and rail.

The derailment coefficients of the two profiles are close to each other under different curve radius, and both increase fastly when the radius $R \leq 500 \mathrm{~m}$. As shown in Figure 20, the original profile has a higher value in the case of $R=800 \mathrm{~m}$, which is due to the contact between wheel flange and rail. The maximum derailment coefficient in the figure is close to 0.4 , and it is much lower than the safety limit. Therefore, both of the profiles can meet safety requirements.

3.2.3. Curve Negotiation Performance on Large Curved Track. In addition to the tangent track, China's high-speed lines mostly compose of large curved tracks. The curve negotiation performances when the vehicle passes through an ideal smooth track and track considering the measured spectrum excitation of the Beijing-Tianjin track are presented, respectively. In the numerical calculation, the actual curve parameters of the newly built high-speed railway are 


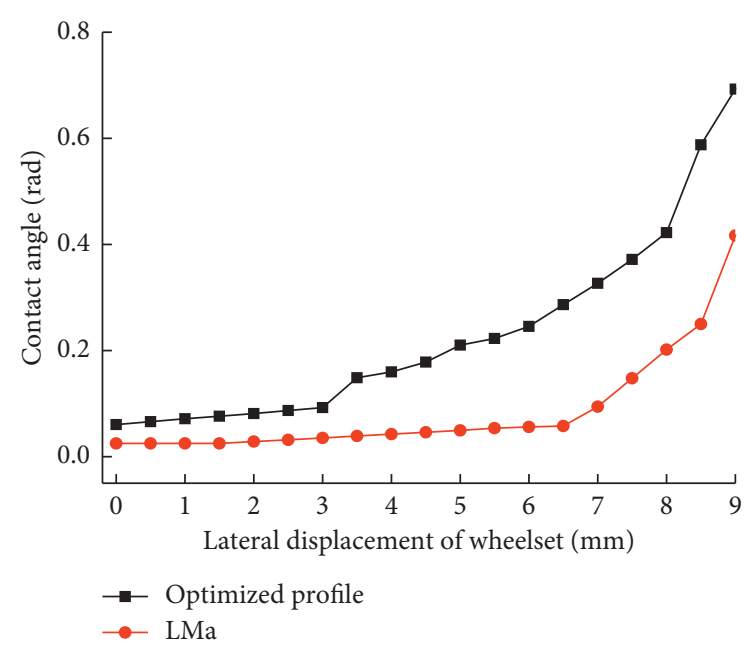

FIgure 16: Contact angle of the wheel and rail.

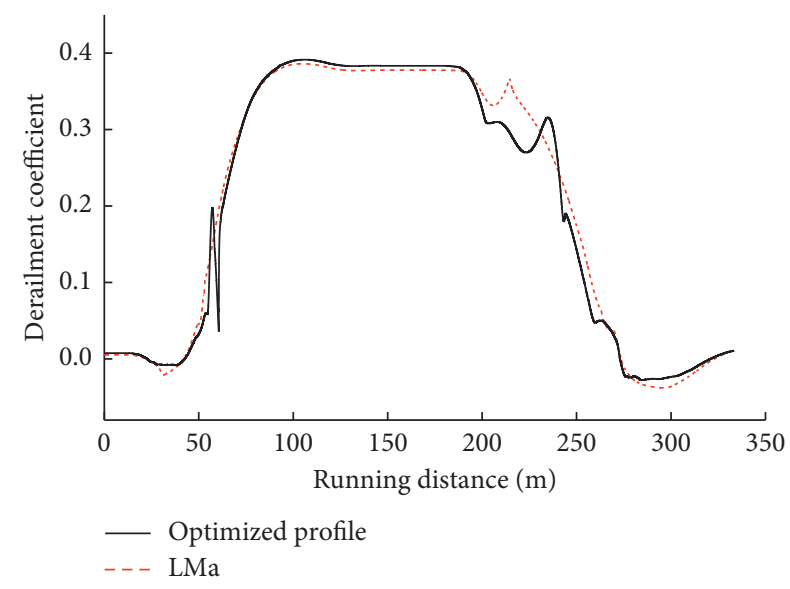

Figure 17: Comparison of derailment coefficient.

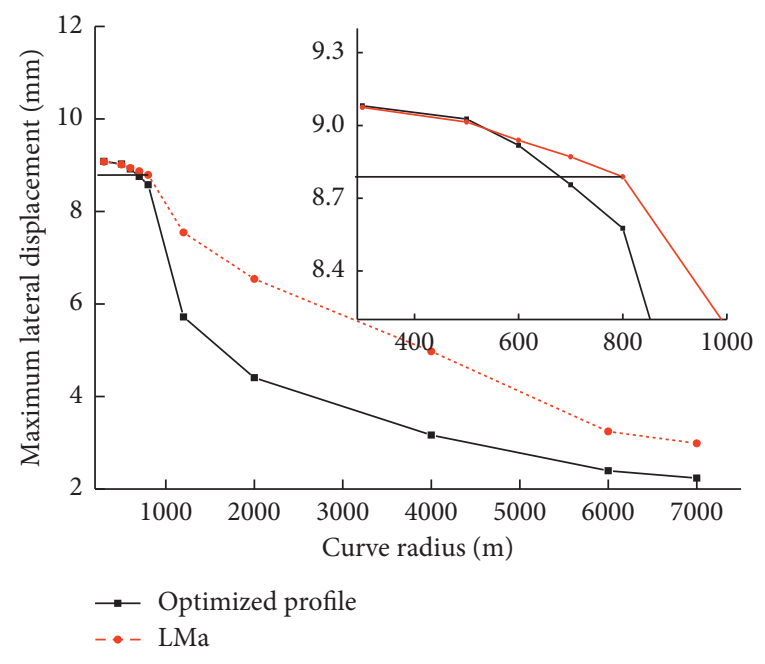

Figure 18: Maximum lateral displacement.

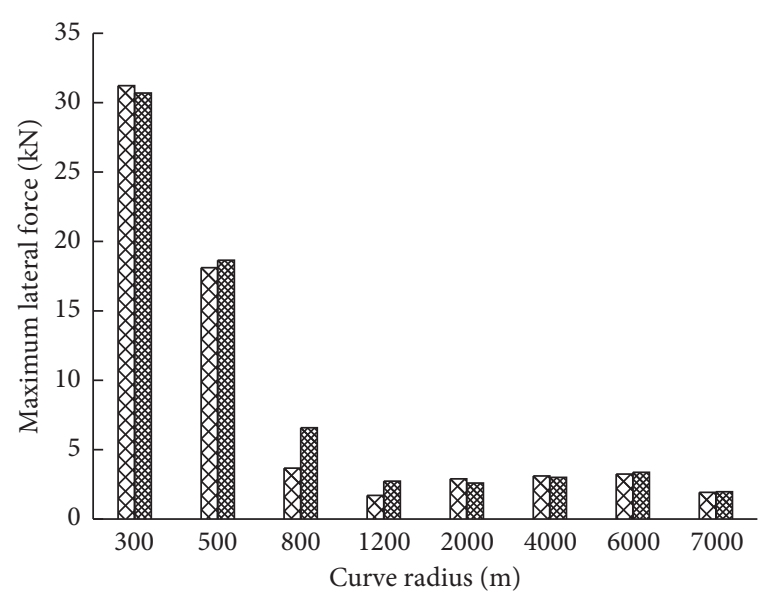

Optimized profile

LMa

FIgURE 19: Maximum lateral force.

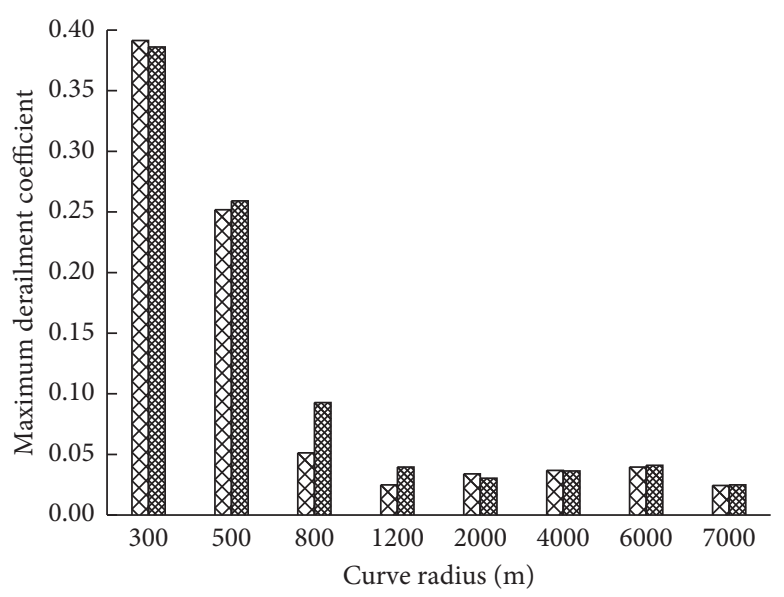

Optimized profile LMa

Figure 20: Maximum derailment coefficient.

adopted. In the curved section, the lateral displacement of the guide wheelset is the largest. The simulation results of the guide wheelset in different conditions are given as an example for the calculation of a large curved track. Figure 21 shows the lateral displacement of the wheelset when the vehicle passes through the ideal track at a speed of $300 \mathrm{~km} / \mathrm{h}$. It shows that a small amplitude of vibration occurs on the transition part of the track. In the whole running distance, the lateral displacement of the optimization profile is significantly smaller due to the higher rolling radii difference, which can provide a larger guiding force. The improved curving performance of the optimization profile can reduce the contact probability between wheel flange and rail, which is helpful to cut down wheel flange wear.

When the vehicle passes through the curve with the measured Beijing-Tianjin track spectrum at different speeds, 


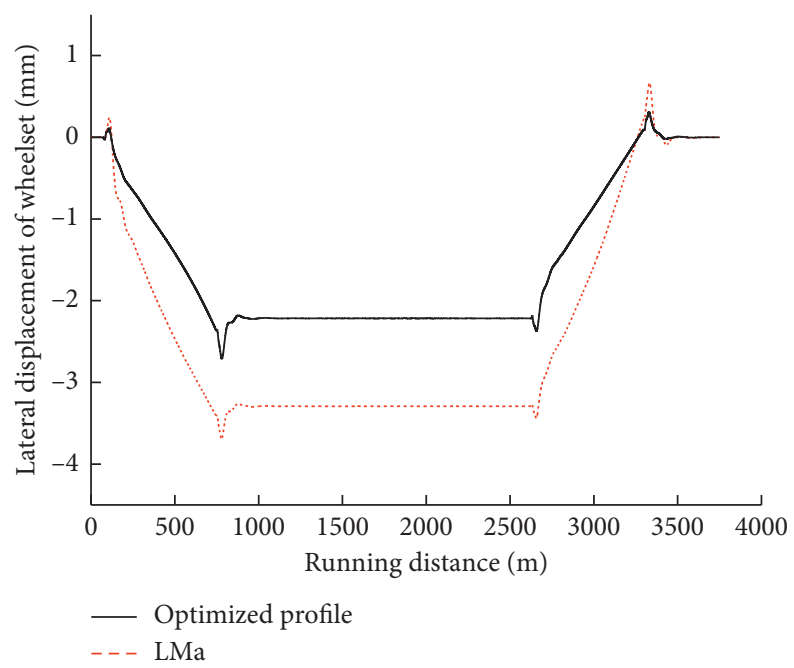

FIgURE 21: Lateral displacement of the wheelset.

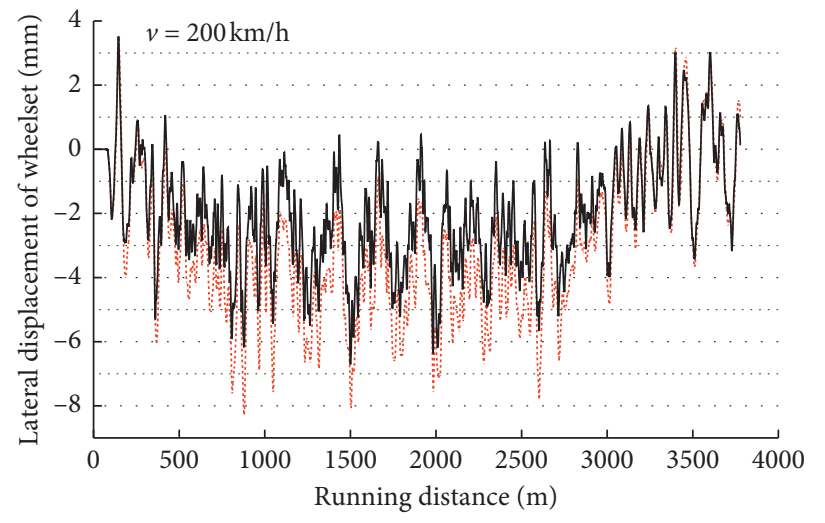

- - LMa

Optimized profile

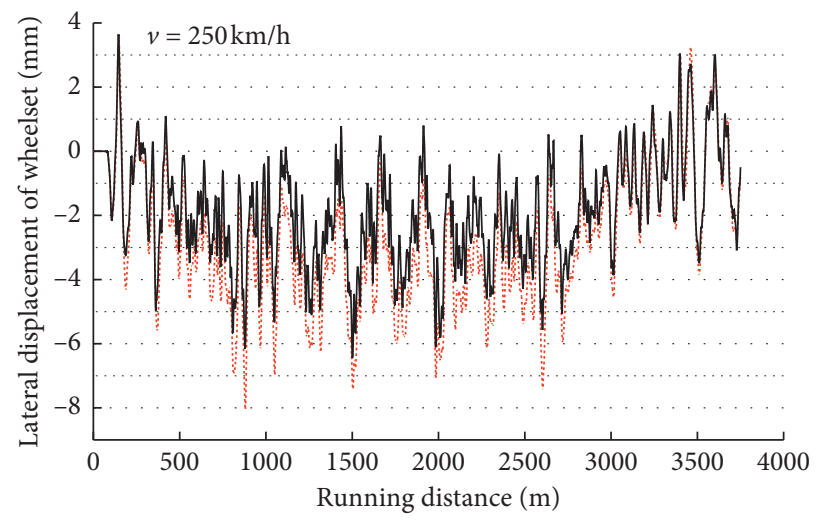

- _- LMa

— Optimized profile

(a)

(b)

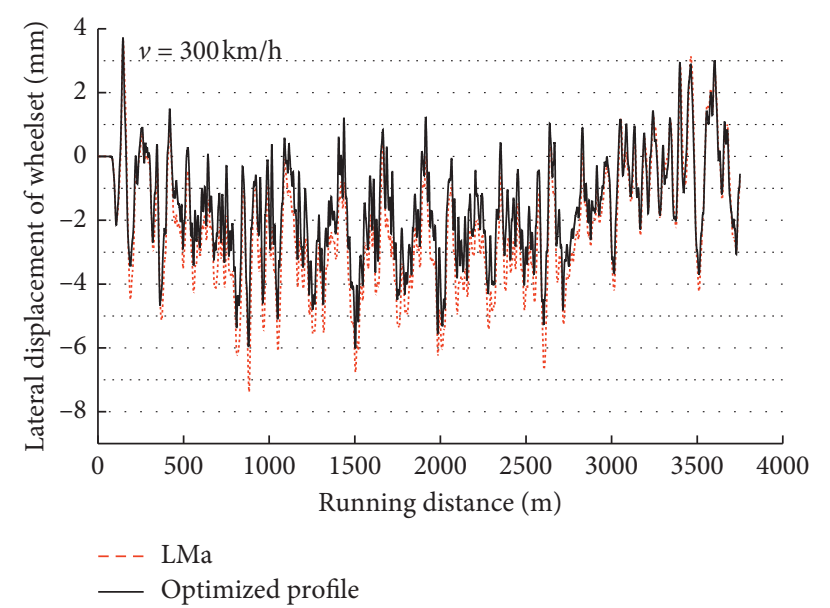

(c)

FiguRE 22: Lateral displacement of the wheelset response under different speeds. 


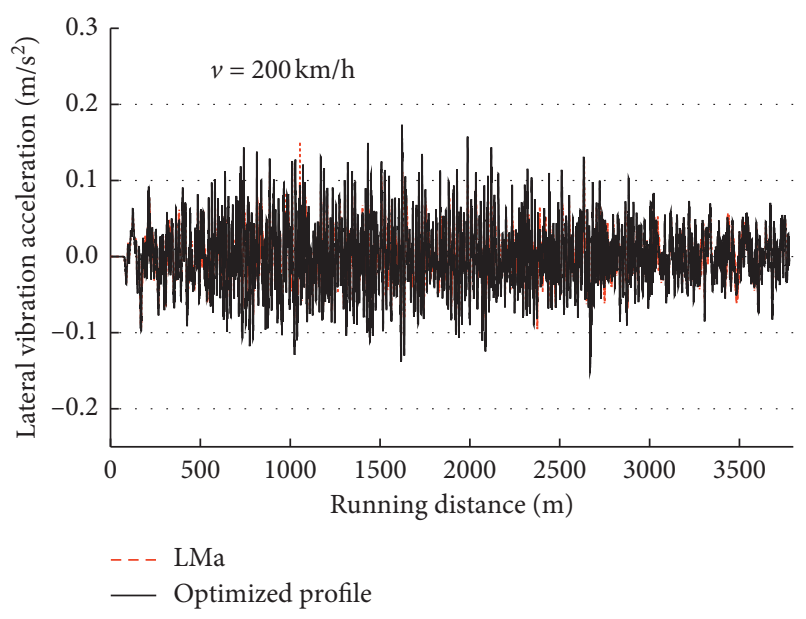

(a)

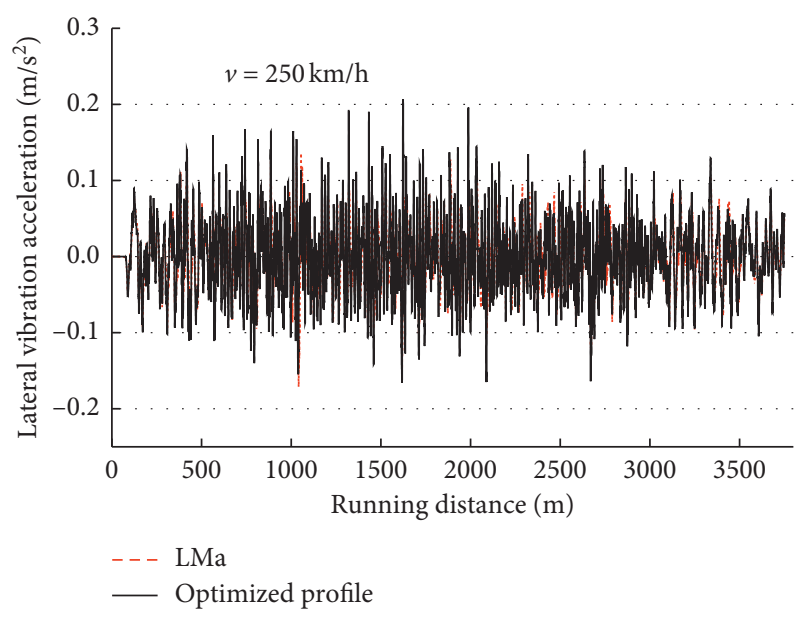

(b)

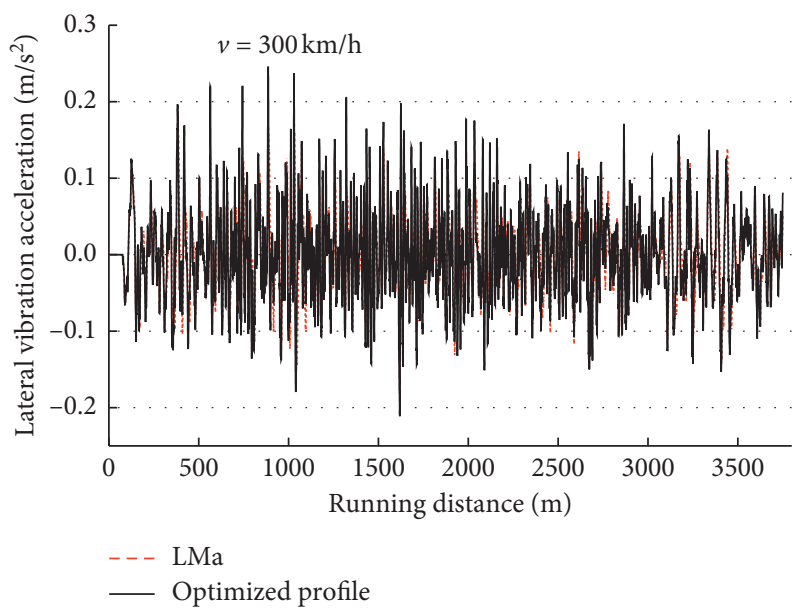

(c)

FiguRE 23: Lateral vibration acceleration under different speeds.

the dynamic behavior is simulated in Figures 22 and 23. The lateral displacement of the OPT wheelset is smaller than that of the original one at different speeds, which means the optimization profile has better centering performance in comparison. In Figure 22, the lateral displacement fluctuations on the transition curve section become less distinct under the influence of track irregularities. Besides, as the running speed increased, the lateral displacement of the twoprofile wheelset tends to decrease, which is related to the steady-state of the vehicle when passing through the curved track.

Figure 23 shows the lateral vibration acceleration of the vehicle body. The vehicle speeds are set at 200, 250, and $300 \mathrm{~km} /$ h. Under the action of track excitation, the effect of curve parameters is not apparent. As the running speed increased, the lateral vibration acceleration of the vehicle body increases gradually, and the amplitude of lateral vibration acceleration of the optimization profile is greater at the same speed. Lateral vibration acceleration has a considerable impact on the lateral stability of the vehicle body. Thus, the lateral stabilization of the vehicle body with the optimized wheelset will decrease.
The root mean square (RMS) value of the wear index of two profiles when the vehicle passes the curve at different speeds is calculated, as shown in Figure 24. On the large curved track, the difference of RMS value of wear index at different velocities is very little, and both keep at a low level, which means the average wheel-rail wear of the two profiles is small under this condition.

3.2.4. Dynamic Performance on Tangent Track. As the straight-line running performance and the curving performance restrict each other, the centering performance is described when a lateral displacement excitation is applied, as shown in Figure 25. As the lateral displacement response of the guide wheelset is the highest, its simulation values are given. The lateral displacement of the optimization profile is always smaller on the tangent track to which the lateral excitation is applied. After the vehicle enters the ideal track, the centering speed of the optimization profile is also significantly faster. The difference between the two wheelsets results from the higher RRD value of the optimization 


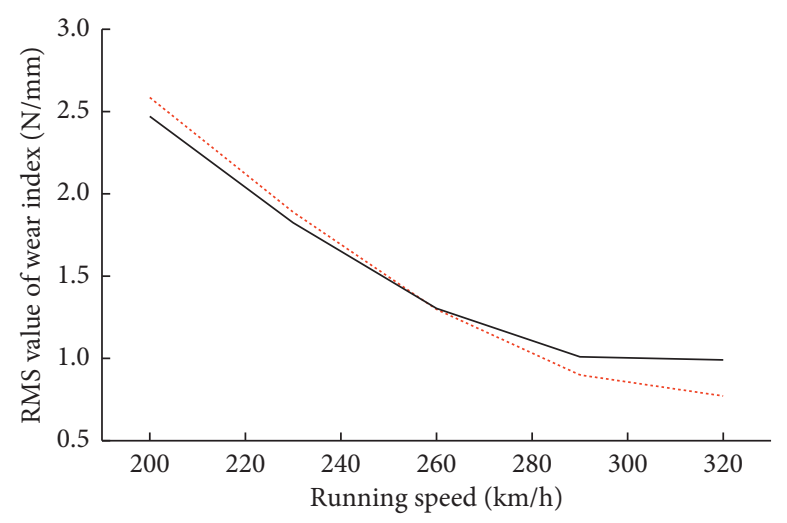

- Optimized profile

- - - LMa

Figure 24: RMS value of the wear index.

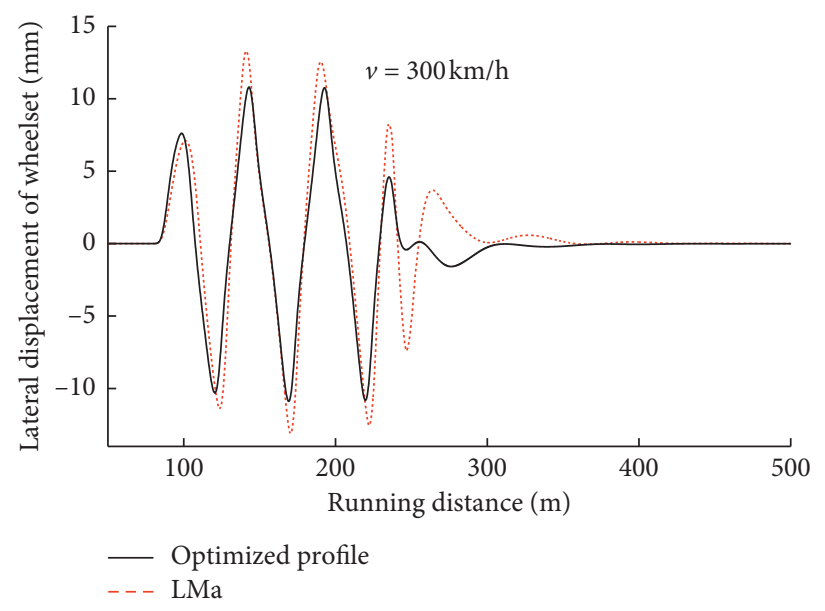

Figure 25: Centering performance of the wheelset.

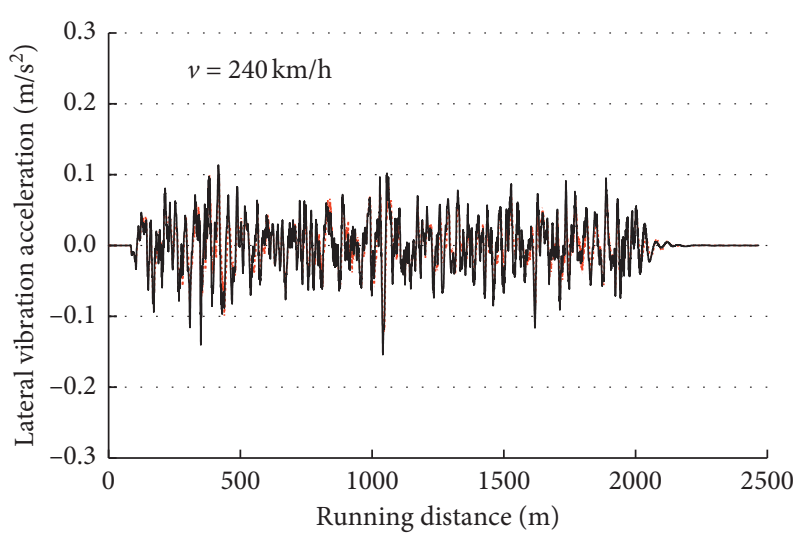

- - - LMa

— Optimized profile

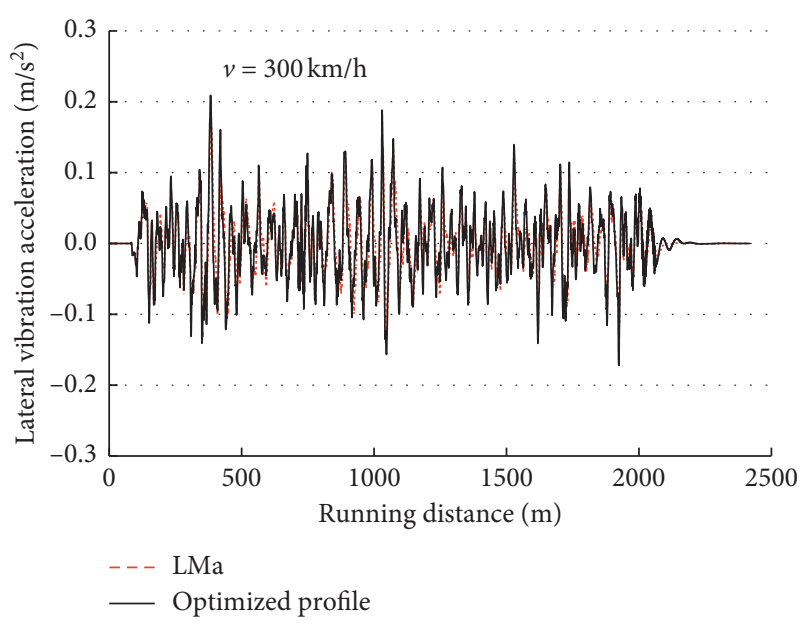

(b)

(a)

FIgURE 26: Continued. 


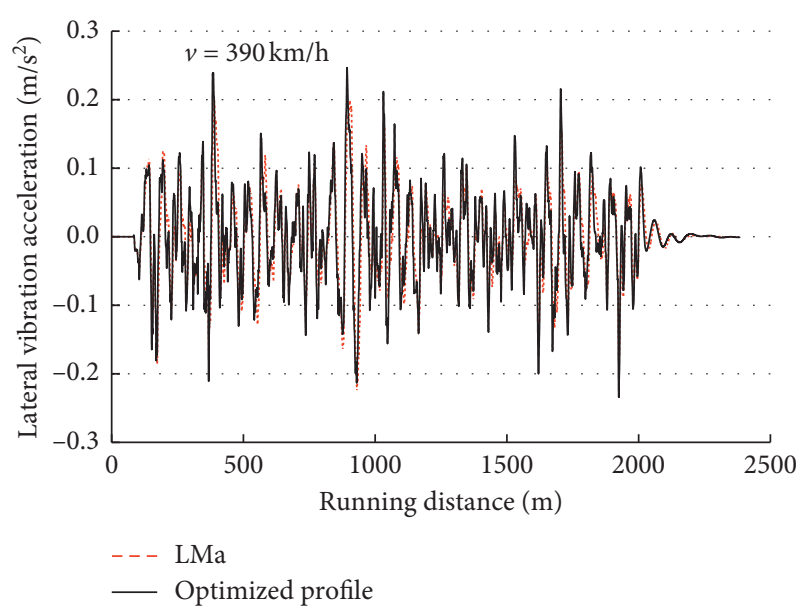

(c)

Figure 26: Lateral vibration acceleration under different speeds.

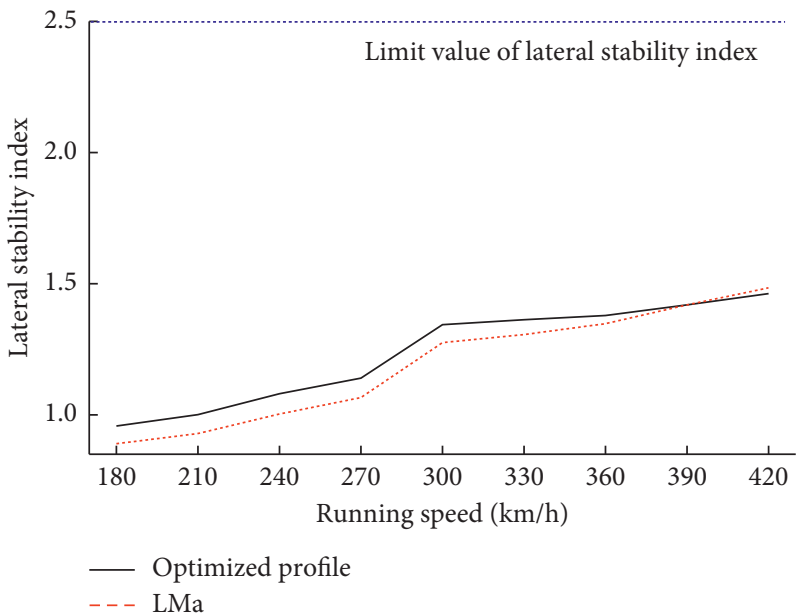

Figure 27: Lateral stability index of the vehicle.

profile, as shown in Figure 7. The critical hunting speed of the vehicle is calculated by the lateral vibration acceleration method. The critical hunting speed of the optimization profile is $470 \mathrm{~km} / \mathrm{h}$, which is lower than the $553 \mathrm{~km} / \mathrm{h}$ of the original one. It can meet the speed requirements of highspeed vehicles.

The lateral vibration acceleration of the vehicle body, when passing through a tangent track with measured track excitation at different speeds, is shown in Figure 26. The acceleration increases with the increase of velocity, and the acceleration difference between the optimization profile and the original one is small at low speed. At high speed, the acceleration of the optimization profile is higher, which is due to the increase of equivalent conicity. Equivalent conicity is considered as the direct index of the hunting motion of the wheelset. However, the lateral vibration acceleration of the optimization profile can still meet the operation requirements.

Figure 27 depicts the lateral stability index of the vehicle body at different speeds, which is significant for the straight- line running performance. The lateral stability index of the two profiles also has an upward trend. When the velocity is at a low level, the stability index of the optimization profile is higher, but the difference gradually decreases as the speed increased. When it reaches $390 \mathrm{~km} / \mathrm{h}$, the stability of the two wheelsets is almost coincident. In particular, the stability index of both wheelsets is significantly lower than 2.5 of EMU with a speed of more than $200 \mathrm{~km} / \mathrm{h}$. Therefore, the optimization profile meets the requirements of high-speed vehicles for straight-line stability. The vertical stabilization of the vehicle body is less affected by the geometric shape of the wheelset [6], so no further analysis is needed here.

\section{Conclusions}

In this paper, based on the field test data of wheel flange wear on a high-speed line, the authors have presented a work focused on an improved parallel reverse design method for the reduction of wheel flange wear on the premise of ensuring the dynamic behavior of the vehicle. This 
optimization method is able to search the target performance curve automatically and obtain the optimization profile without artificial experience, all of which are conducive to the application of the method. Comparative results obtained from the simulation in terms of flange wear, wheel tread wear, and dynamic performance prove the effectiveness and convenience of the proposed method.

The contrast analysis shows that the rolling radii difference, which is proportional to equivalent conicity, of the optimization profile is increased when the lateral displacement exceeds $3 \mathrm{~mm}$. And the lower value under small lateral displacement ensures the straight-line running performance. Besides, the larger creep force of the optimization profile can provide a better guiding force. On a sharp curve, when the two-point contact occurs, the optimization profile reduces the wheel flange force, and the curve radius of two-point contact is smaller. Moreover, the average wear of the two profiles on a large curved track is similar, and the critical speed and lateral stability index of the vehicle on tangent track are guaranteed. In general, the optimization profile improves the wheel flange wear on the tight curve and ensures the dynamic behavior on tangent track and large curved track. The purpose of profile optimization is realized. Next, the field tests of the optimization profile are necessity. Besides, the traction for wheels is not possible to be taken into consideration currently. This will be a follow-up work.

\section{Data Availability}

The data are available from the corresponding author or the first author upon request.

\section{Conflicts of Interest}

The authors declare no conflicts of interest.

\section{Authors' Contributions}

Dabin Cui conceived the method. Wenjuan Ren built the model, analyzed the results, and wrote the paper. $\mathrm{Li} \mathrm{Li}$ supervised the entire work. Guangxiong Chen checked part of the paper.

\section{Acknowledgments}

The present work was supported by the Sichuan Science and Technology Program (2020YJ0308).

\section{References}

[1] W.-J. Wang, Z.-K. Fu, J. Guo et al., "Investigation on wear resistance and fatigue damage of laser cladding coating on wheel and rail materials under the oil lubrication condition," Tribology Transactions, vol. 59, no. 5, pp. 810-817, 2016.

[2] D. B. Zhang, "On wheel-rail profile optimization for railway vehicle," Master thesis, Southwest Jiaotong University, Chengdu, China, 2009.

[3] J. Zhang, Z. F. Wen, L. P. Sun, and X. S. Jin, "Wheel profile design based on rail profile expansion method," Chinese
Journal of Mechanical Engineering, vol. 44, no. 3, pp. 44-49, 2008.

[4] I. Y. Shevtsov, V. L. Markine, and C. Esveld, "Optimal design of wheel profile for railway vehicles," Wear, vol. 258, no. 7-8, pp. 1022-1030, 2005.

[5] O. Polach, "Wheel profile design for target conicity and wide tread wear spreading," Wear, vol. 271, no. 1-2, pp. 195-202, 2011.

[6] D. B. Cui, "Study on wheel profile design method for highspeed train," Doctor thesis, Southwest Jiaotong University, Chengdu, China, 2013.

[7] J.-w. Seo, S.-j. Kwon, H.-k. Jun, and C.-w. Lee, "Effects of wheel materials on wear and fatigue damage behaviors of wheels/rails," Tribology Transactions, vol. 62, no. 4, pp. 635-649, 2019.

[8] X. S. Jin and Q. Y. Liu, Tribology of Wheel and Rail, China Railway Publishing House, Beijing, China, 2004.

[9] M. R. Hou and W. D. Wang, "A study of rail wear on sharp curves in EMU maintenance depot," Journal of the China Railway Society, vol. 40, pp. 45-50, 2018.

[10] G. Shen and D. X. Zhang, "Research on readjust rail inclinations for reducing rail side-cutting," Journal of the China Railway Society, vol. 16, pp. 95-99, 1994.

[11] P. Chen and L. Gao, "Simulation study on parameters influencing wheel/rail wear in radius way curve," China Railway Science, vol. 28, pp. 19-23, 2007.

[12] K. T. Wang, X. F. Zhang, H. T. Zhou, and J. Liang, "Research on abnormal wheel-flange wear of CRH1 EMU and it's solutions," Railway Locomotive \& Cars, vol. 39, pp. 114-117, 2019.

[13] B. Wen and G. Q. Tao, "Effects of metro wheel flange lubrication on wheel wear," Electric Drive for Locomotives, vol. 6, pp. 101-105, 2017.

[14] D. X. Ren, "Research on optimization of metro wheel profile for low flange wear," Master thesis, Southwest Jiaotong University, Chengdu, China, 2019.

[15] D. Cui, R. Wang, P. Allen, B. An, L. Li, and Z. Wen, "Multiobjective optimization of electric multiple unit wheel profile from wheel flange wear viewpoint," Structural and Multidisciplinary Optimization, vol. 59, no. 1, pp. 279-289, 2019.

[16] W. J. Ren, D. B. Cui, L. Li, and J. Su, "Influence of wheel reprofiling on wheel-rail profile matching performance," $L u$ brication Engineering, vol. 40, pp. 16-21, 2015.

[17] W. J. Lu and G. Q. Tao, "Influence of wheel wear on wheel-rail contact behavior and dynamic performance of metro vehicle," Engineering Mechanics, vol. 34, pp. 222-231, 2017.

[18] C. X. Sun and J. Zhang, "Analysis on matching of worn wheelrail profile in curve section," Journal of China Railway Society, vol. 36, pp. 35-39, 2014.

[19] V. L. Markine, I. Y. Shevtsov, and C. Esveld, "An inverse shape design method for railway wheel profiles," Structural and Multidisciplinary Optimization, vol. 33, no. 3, pp. 243-253, 2007.

[20] B. Xue, D. B. Cui, L. Li et al., "Parallel inverse design method of wheel profile," Journal of Mechanical Engineering, vol. 49, no. 16, pp. 8-16, 2013.

[21] S. L. Lian, "Analysis of the cause of alternating side wear of rail on tangent," China Railway Science, vol. 22, pp. 107-111, 2001.

[22] M. R. Chi, W. H. Zhang, J. Zeng et al., "Influence of wheel diameter difference on the stability of vehicle system," China Railway Science, vol. 29, pp. 65-69, 2008.

[23] M. Avriel, Nonlinear Programming: Analysis and Methods, Prentice-Hall, Inc., Upper Saddle River, NJ, USA, 1976. 
[24] Z. J. Geng, "Study of the nonlinear programming simplex method," Master thesis, Beijing Jiaotong University, Beijing, China, 2008.

[25] Y. S. Yu and W. Z. Huang, "New simplex optimization algorithm-quasi optimal direction search method," Mach. Des. Res.vol. 2, pp. 33-38, 1985.

[26] W. M. Zhai, Vehicle-Track Coupled Dynamics, CSPM, Beijing, China, 4th edition, 2020.

[27] M. R. Chi, W. H. Zhang, and J. Zeng, "Influence of wheeldiameter difference on running security of vehicle system," Journal of Traffic and Transportation Engineering, vol. 8, pp. 19-22, 2008. 